\title{
Effect of Different Silane-Containing Solutions on Glass-Ceramic/ Cement Bonding Interacting with Dual-Cure Resin Cements
}

\section{Efecto de Diferentes Soluciones Silanizadoras en la Interface Adhesiva Cerámica Vítrea/Cemento y su Interacción con Cementos Resinosos de Curado Dual}

\author{
Fabián Murillo Gómez DDS, Msc; Mário Fernando De Góes DDS, Msc, PhD¹ \\ 1. Dental Materials Area-Department of Restorative Dentistry, \\ Piracicaba School of Dentistry-Universidad de Campinas, Brasil.
}

Correspondence to: Dr. Fabián Murillo Gómez - fdam17@hotmail.com

Received: 26-VI-2015

Accepted:30-VI-2015

\section{ABSTRACT}

The aim of this study is to determine the effect of different silane-containing solutions on ceramic-cement bonding and their interaction with different dual-cure resin cements. Forty five glassceramic plaques (IPS e.max CAD®) were sandblasted with aluminum oxide for 5 s, etched with $10 \%$ hydrofluoric acid gel (HF) for 20s and then divided in three groups of 15 each to be treated with different silane-containing solutions: RelyX Ceramic Primer ${ }^{\circledR}(A S)$, Scotchbond Universal ${ }^{\circledR}$ (SU), Clearfil Ceramic Primer ${ }^{\circledR}(\mathrm{CP})$. Then each group was divided in five groups of three plaques to receive the following dual-cure resin cements: Conventional: RelyX Ultimate (RU), RelyX ARC (AR), VarioLink II (VL); and two self-adhesive: RelyX UNICEM 2 (U2), and BiFix (BF). Eight cement cylinders of each cement were distributed on each plaque and polymerized, summarizing 24 cylinders per group. After $24 \mathrm{~h}$ storage in relative humidity at $37^{\circ} \mathrm{C}$, each cylinder was subjected to a microshear testing. Failure mode was analyzed using scanning electron microscopy (SEM). Data were statistically analyzed with two-way ANOVA (resin cement and silane ) and Tukey test $(p \leq 0.05)$. Both factors significantly influenced the results and also interaction between them was detected ( $p=0.0001)$. $\mu$ SBS was significantly higher when ceramic was treated with AS for all cements. Most of cements showed no statistically different means when treated with SU and CP, except BF-SU and AR-CP that showed significantly lower means within their treatment groups. Some incomplete polymerization areas were observed in SEM images for those cases. Cohesive failure in resin cement type was predominant with higher results while adhesive with lower results. The sole silane solution improved better bonding than the universal adhesive and the ceramic primer. In general, universal adhesive and ceramic primer produced acceptable mean values and they were statistically comparable. Compatibility between silane solutions and dual-cure resin cements may be material dependent.

\section{CLINICAL RELEVANCE}

Simplified adhesives and primers containing silane may also improve ceramic-cement bond strength but in a lower degree than conventional silane-solutions. Interaction of those solutions with different resin cements may be material dependent, so the clinician may be warned of using a compatible material combination.

MURRILLO, F. \& DE GÓES, M., 2014: Effect of Different Silane-Containing Solutions on Glass-Ceramic/Cement Bonding Interacting with DualCure Resin Cements.-ODOVTOS-Int. J. Dental S.C., 16: 87-105. 


\section{KEYWORDS}

Adhesive bond, microshear test, resin cements, silane solutions

RESUMEN

El objetivo de este estudio fue determinar el efecto de diferentes soluciones silanizadoras en la interface adhesiva cerámica-vítrea/cemento y su interacción con diferentes cementos resinosos de curado dual. Cuarenta y cinco placas vitro-cerámicas (IPS e.max CAD®) fueron arenadas con óxido de aluminio por 5s, grabadas con gel de ácido fluorhídrico al 10\% (HF) por 20 seg. y posteriormente se dividieron en tres grupos de 15 cada uno para ser tratados con diferentes soluciones silanizadoras: RelyX

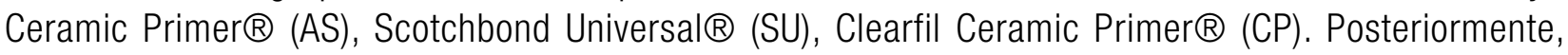
cada grupo se dividió en cinco subgrupos de tres placas para recibir los respectivos cementos resinosos de curado dual: Convencional: RelyX Ultimate (RU), RelyX ARC (AR), VarioLink II (VL); y dos autoadhesivos: RelyX UNICEM 2 (U2), and BiFix (BF). Ocho cilindros de cada cemento se distribuyeron en cada placa y se polimerizaron, en resumen se utilizaron 24 cilindros por grupo. Después de $24 \mathrm{~h}$ de almacenamiento en humedad relativa a $37^{\circ} \mathrm{C}$, cada cilindro se sometió a una prueba de microcisallamiento. El tipo de fractura se analizó mediante microscopía electrónica de barrido (MEB). Los datos fueron analizados estadísticamente con ANOVA (cemento de resina y silano) y la prueba de Tukey $(p=0.05)$. Ambos factores influyeron de manera significativa en los resultados y también se detectó interacción entre ellos ( $p=0,0001$ ). $\mu$ SBS fue significativamente mayor cuando la cerámica fue tratada con AS en todos los cementos evaluados. La mayoría de los cementos no mostraron diferencias estadísticamente significativas cuando fueron tratados con SU y CP, excepto BF-SU y AR-CP Ios cuales mostraron medias significativamente menores dentro de sus grupos de tratamiento. En las imágenes de MEB se observaron algunas zonas de polimerización incompleta en esos casos. El tipo de fractura cohesiva ene el cemento estuvo asociada a valores mayores de resistencia de unión, mientras que la fractura de tipo adhesiva con valores menores. De manera general, el adhesivo universal y el primer cerámico produjeron valores aceptables y fueron estadísticamente comparables. La compatibilidad entre las soluciones silanizadoras y los cementos resinosos de curado dual puede ser material dependiente.

\section{RELEVANCIA CLÍNICA}

Los adhesivos simplificados y los primers que contienen silano pueden mejorar la resistencia de unión de la interface cerámica-cemento, pero en un grado menor que las soluciones de silano convencionales. La interacción de esas soluciones con diferentes cementos resinosos podría ser material dependiente, por lo que el clínico debe estar consciente de utilizar una combinación de materiales que sean compatibles entre sí.

\section{PALABRAS CLAVE}

Adhesión, prueba de microcisallamiento, cementos resinosos, soluciones silanizadoras

\section{INTRODUCTION}

Dental ceramics became one of the mostly used restorative materials in the last years for esthetic and rehabilitation procedures due to various positive properties in topics as wear resistance, biocompatibility, thermal conductivity and optical characteristics (Denry\&Kelly, 2008; 
Kelly\&Denry, 2008). However, to obtain an optimal bonding of the ceramic restoration to tooth structure it is required, surface treatment in dental tissues (Peumans et al., 2010), ceramic material (Brentel et al., 2007) and the use of luting agents.

Different kinds of luting agents have been used to bond ceramic restorations to tooth structure (Edelhoff\&Özcan, 2007). Resin-based polymerizing cements can perform some chemical and mechanical interaction to tooth and restoration (Peumans et al., 1999; De Munck et al.2005). Furthermore, they present superior bond strength to tooth and ceramics than water-based cements, low solubility, adhesion capability and long-term stability with silica-based ceramics (Sadowsky, 2006; Kramer et al., 2000). Resin cements may be bonded to the tooth using either the etchand-rinse or self-etch adhesive technique, also other kind of resin cements may not need an intermediate adhesive system to bond the tooth structures and they are called self-adhesive resin cements (Ferracane et al., 2011).

To achieve adhesion between resin cement and glass-ceramic material, there are two main approaches: micromechanical interlocking and chemical bonding (Tian et al., 2014). Mechanical attachment can be promoted by etching the glassceramic surface (commonly with hydrofluoric acid (HF)) (Filho et al., 2004) and sandblasting (Moharamzadeh et al., 2008), while silane may produce chemical adhesion (Matinlinna et al., 2004). The combination of both mechanical and chemical bonding is the preferred way to establish an optimal resin-cement/glass-ceramic bond (Blatz et al., 2003; Brentel et al., 2007; Lung\&Matinlinna, 2012).

Since 1977, silane coupling agents have been applied as adhesion promoters in dentistry (Eames et al., 1977). Moreover, silane coupling agents must be activated through a hydrolyzation process $(\mathrm{SiOR} \longrightarrow \mathrm{SiOH})$, so they could be able to bond through $\mathrm{OH}$ groups (Lung\&Matinlinna, 2012). So, many commercial silane-solutions use a molecule with a pre-hydrolyzed silane group in one side and a methacrylate group in the other side (3-Methacryloxypropyltrimethoxysilane, MPS) in order to bond resin and ceramic, and using ethanol and water as solvents in one bottle (Anagnostopoulos et al., 1993).

Likewise, it has been suggested that solutions containing phosphate acid monomers such as MDP (10-methacryloyloxydecyl dihydrogen phosphate) may also improve ceramic-resin bonding (Blatz et al., 2004). Those phosphate acid monomers are employed due to their capability to bond metallic ions present in some ceramics (mainly non-glass ceramics) with methacrylate groups in resin cements (Blatz et al., 2004; Kitayama et al, 2010). Thus, when silane is added along (as in some commercial primers), that solution can enhance bonding in glass ceramics and non-glass ceramics indistinctly. Additionally, these phosphate acid monomers are also incorporated in some enameldentin self-etch adhesives to act as couplers between methacrylate groups and calcium present in enamel and dentin (Van Meerbeek et al., 2011). Recently, silane has been also added to those adhesives obtaining a "universal" bonding solution to be used with enamel, dentin, ceramics and some metal alloys, possibly simplifying clinical steps (Van Meerbeek et al., 2003). This broad range of silane-containing solutions are supposed to act as conventional silane couplers, but there is no further evidence that clears if they can improve equally the ceramic-cement bonding and how they interact with different kinds of resin cements.

The aim of this in vitro study is to determine the effect of different silane-containing solutions on ceramic-cement bonding and their interaction with different dual-cure resin cements. The hypothesis set in this study was that ceramic-cement $\mu \mathrm{SBS}$ could be influenced by the usage of different resin cements and silane-solutions. 
MATERIALS AND METHODS

One glass-ceramic (IPS e-max lithium disilicate CAD/CAM, color A2, Ivoclar, Vivadent, NY, USA; Lot. N76665) was used as a substrate to bond five different dual-cure resin cements which three are conventional adhesive resin cements (all in A2 shade): RelyX Ultimate (RU) (3M ESPE, St. Paul, MN, USA/Neuss, Germany), RelyX ARC (AR) (3M ESPE), VarioLink II (VL) (Ivoclar Vivadent AG, Schaan, Liechtenstein); and two self-adhesive resin cements: RelyX UNICEM 2 (U2) (3M ESPE), and BiFix (BF) (VOCO $\mathrm{GmbH}$, Cuxhaven, Germany) (Table 1). Three silane-containing solutions were employed as silanization treatment: RelyX Ceramic Primer (AS) -a sole-silane solution- (3M ESPE), Scotchbond Universal (SU) -a built-in-silane multi-mode adhesive- (3M ESPE) and Clearfil Ceramic Primer (CP) -a ceramic primer containing silane and MDP- (Kuraray Noritake Dental Inc., Okayama, Japan) (Table 1). The specimens preparation methodology for the microshear bond strength test ( $\mu \mathrm{SBS})$ was adapted from the one developed by Shimada (Shimada et al., 2002).

Forty five lithium disilicate ceramic plaques measuring $10 \pm 0.1 \mathrm{~mm}$ in length, $6 \pm 0.1 \mathrm{~mm}$ in width and $2 \pm 0.1 \mathrm{~mm}$ in thickness were milled from pre-sintered CAD/CAM blocks on an E4D Dentist System (D4D technologies, LLC, Richardson, TX, USA) using a custom-mill file. They were sandblasted with aluminum oxide $(50 \mu \mathrm{m}$; BioArt, São Carlos, SP, Brazil) at 2 bar pressure for 5 seconds in only one surface at a working distance of $5 \mathrm{~mm}$ from the ceramic plaque. They were also treated with $10 \%$ Hydrofluoric acid gel (HF) (Porcelain Conditioner Dentsply, Petropolis, Brazil) for 20 seconds (Borges et al., 2003) and washed with tap water for 1 minute. Then all plaques were ultrasonically cleaned for 5 minutes in distilled water and air-dried. Each ceramic plaque was prepared to receive 8 resin-cement cylinders.
All the 45 glass-ceramic plaques were divided into 3 groups of 15 plaques each to be treated with one of the three silane-solutions. Each group was subsequently divided in 5 groups of 3 plaques to receive each of the cements listed above. All materials' employment protocol is described on Table 2. Each treated glass ceramic plaque was placed in a silicon mold with eight cylindricalshaped compartments measuring $1.6 \pm 0.1 \mathrm{~mm}$ in diameter and $1 \pm 0.1 \mathrm{~mm}$ in thickness. All resin cements were "calibrated", squeezing out the first amount of material until it was delivered evenly from either chambers or dispensers. Then, the resin cement was injected into each compartment on the treated ceramic plaque (8 cement cylinders on each ceramic plate) (Table 2) and light-cured (Optilight Max, Gnatus, Brazil; light output: $600 \mathrm{~mW} / \mathrm{cm} 2)$ for $40 \mathrm{~s}$. A $1 \mathrm{~mm}$ glass slide was placed between the light tip and the cylindrical resin cement specimen. The ceramicplaque/resin-cement assemblies were removed from the molds after 5 minutes, summarizing 24 cylinders for each group. The specimens were water rinsed, dried and stored in 100\% relative humidity at $37^{\circ} \mathrm{C}$ for $24 \mathrm{~h}$.

Specimens were attached to a holding device with cyanoacrylate glue (Super Bonder Loctite, Henkel) and placed on a universal testing machine (Instron 4411, Instron Corporation, Canton, MA, USA) in order to do microshear bond test ( $\mu S B S$ ) using a 500-N load cell. A shear load was applied to the base of the resin cement cylinder with a thin wire $(0.20 \mathrm{~mm}$ diameter $)$ placed strictly parallel to the ceramic plaque surface at a crosshead speed of $0.5 \mathrm{~mm} / \mathrm{min}$. Values of each specimen were expressed in $\mathrm{MPa}$, and then a group mean was calculated (24 measures). All data were statistically analyzed by TwoWay ANOVA (resin cement vs. silane containing solution) and Tukey test at a significance level of $5 \%(p<0.05)$. The hole methodology procedure is illustrated on Scheme 1. 
Table 1. List of all materials used and their composition.

\begin{tabular}{|c|c|c|}
\hline Material & Lot./Manufacturer & Composition* \\
\hline $\begin{array}{l}\text { RelyX Ceramic } \\
\text { Primer } \\
\text { (AS }\end{array}$ & $\begin{array}{l}\text { N406850/ 3M ESPE, } \\
\text { St. Paul, MN, USA }\end{array}$ & MPS, ethanol, water. \\
\hline $\begin{array}{l}\text { Scotchbond } \\
\text { Universal Adhesive } \\
\text { (SU) }\end{array}$ & $\begin{array}{l}\text { 504115/ 3M ESPE, } \\
\text { St. Paul, MN, USA/ } \\
\text { Neuss, Germany }\end{array}$ & $\begin{array}{l}\text { Bis-GMA, HEMA, decamethylene dimethacrylate, ethanol, water, silane treated silica, } \\
\text { 2-propenoic acid, 2-methyl-, reaction products with 1,10-decanediol and phosphorous } \\
\text { oxide (P205), copolymer of acrylic and itaconic acid, dimethylaminobenzoat(-4), } \\
\text { camphorquinone, (dimethylamino) ethyl methacrylate } 2 \text { methyl ethyl ketone, silane, MDP. }\end{array}$ \\
\hline $\begin{array}{l}\text { Clearfil Ceramic } \\
\text { Primer } \\
\text { (CP) }\end{array}$ & $\begin{array}{l}\text { 00023D/ Kuraray } \\
\text { Noritake Dental Inc., } \\
\text { Okayama, Japan }\end{array}$ & MPS, MDP, ethanol. \\
\hline $\begin{array}{l}\text { RelyX Ultimate- } \\
\text { Adhesive Resin } \\
\text { Cement- Automixing } \\
\text { (RU) }\end{array}$ & $\begin{array}{l}\text { 505370/ 3M ESPE, } \\
\text { St. Paul, MN, USA/ } \\
\text { Neuss, Germany }\end{array}$ & $\begin{array}{l}\text { Base: silane treated glass powder, 2-propenoic acid, 2-methyl-, 1,1'-[1-(hydroxymethyl)- } \\
\text { 1,2-ethanediyl] ester, reaction products with 2-hydroxy-1,3-propanediyl dimethacrylate } \\
\text { and phosphorus oxide, TEGDMA, silane treated silica, oxide glass chemicals, sodium } \\
\text { persulfate, tert-butyl peroxy-3,5,5-trimethylhexanoate, copper (ii) acetate monohydrate. } \\
\text { Catalyst: silane treated glass powder, substituted dimethacrylate, 1-benzyl-5-phenyl- } \\
\text { barbic-acid, calcium salt, 1,12-dodecane dimethycrylate, sodium p-toluenesulfinate, silane } \\
\text { treated silica, 2-propenoic acid, 2-methyl-, [(3-methoxypropyl)imino]di-2,1-, ethanediyl } \\
\text { ester, calcium hydroxide, titanium dioxide. }\end{array}$ \\
\hline
\end{tabular}

RelyX UNICEM 2Self-Adhesive Resin Cement- Automixing (U2)
505455/ 3M ESPE, St. Paul, MN, USA/ Neuss, Germany
Base: silanetreated glass powder,2-propenoic acid, 2-methyl-, 1,1'-[1-(hydroxymethyl)-1,2-, ethanediyl] ester, reaction products with 2-hydroxy-1,3-, propanediyl dimethacrylate and phosphorus oxide, TEGDMA, silane treated silica, sodium persulfate, glass powder, tertbutyl peroxy-3,5,5-trimethylhexanoate.

Catalyst: silane treated glass powder, substituted dimethacrylate, 1-benzyl-5-phenylbarbic-acid, calcium salt, silane treated silica, sodium p-toluenesulfinate, 1,12-dodecane dimethycrylate, calcium hydroxide, methacrylated aliphatic amine, methacrylated aliphatic amine, titanium dioxide.

Base: UDMA, GDMA, catalysts, initiators.

Catalyst: GDMA, acidic adhesive monomer, UDMA, Bis-GMA, Hydroxypropyl methacrylate, benzoyl peroxide.

Paste A: silane treated ceramic, TEGDMA, Bis-GMA, silane treated silica, functionalized dimethacrylate polymer, triphenylantimony.

Paste B: silane treated ceramic, TEGDMA, Bis-GMA, silane treated silica, functionalized dimethacrylate polymer, 2-benzotriazolyl-4-methylphenol, benzoyl peroxide.

Base: Bis-GMA, UDMA, TEGDMA, barium glass, ytterbium trifluoride, Ba-Al-fluorsilicate glass, and spheroid mixed oxide.

Catalyst: Bis-GMA, UDMA, TEGDMA, dibenzoil peroxide, catalyst, stabilizers, pigments.
Resin Cement- Two dispensers (VL)
1404800205/3M ESPE, St. Paul MN, USA/Neuss, SP, Brazil

S39795/ Ivoclar Vivadent AG, Schaan, Liechtenstein

*MPS, methacryloxypropyltrimethoxysilane (pre-hydrolyzed silane); MDP, 10-methacryloyloxydecyl dihydrogen phosphate; HEMA, 2-hydroxyethyl methacrylate; Bis-GMA, bisphenol A-diglycidyl ether dimethacrilate; TEGDMA, triethylene glycol dimethacrylate; UDMA, urethane dimethacrylate; GDMA: glycerin dimethacrylate. Composition of the materials according to materials safety data sheets (MSDS) provided by the manufacturers. 
Table 2. List of all materials used and their respective application instructions (according to manufacturers).

Material

RelyX Ceramic Primer

(AS)

Scotchbond Universal Adhesive

(SU)

Clearfil Ceramic Primer

(CP)

RelyX Ultimate- Adhesive Resin CementAutomix (RU)

RelyX UNICEM 2- Self-Adhesive Resin Cement- Automix (U2)

BiFix SE- Self-Adhesive Resin CementAutomix (BF)

RelyX ARC- Adhesive Resin CementClicker (AR)
One layer was applied actively with a microbrush onto the etched glass-ceramic surface for $1 \mathrm{~min}$ and air dried for $5 \mathrm{~s}$.

A thin layer was applied actively with a microbrush onto the etched glass-ceramic surface for 20s; excess was removed with another microbrush and air-dried for 5 s. Adhesive was not polymerized.

One coat was applied actively onto the etched glass-ceramic surface with a microbrush for $1 \mathrm{~min}$ and air-dried for $5 \mathrm{~s}$.

Cement was applied on each mold compartment with an automixing tip (provided by manufacturer) without separating it from the dispensed mass until filling the compartment.

Cement was applied on each mold compartment with an automixing tip (provided by manufacturer) without separating it from the dispensed mass until filling the compartment.

Cement was applied on each mold compartment with an automixing tip (provided by manufacturer) without separating it from the dispensed mass until filling the compartment.

The equivalent amount of four "clicks" per ceramic plaque was dispensed on a mixing paper, both pastes were mixed with a plastic spatula for 10s to obtain a uniform paste, immediately it was charged and dispensed into each mold compartment using a universal syringe (Mark IIIPTM, Centrix, CT, USA) without separating its tip from the dispensed mass until filling the compartment.

The equivalent amount of $2 \mathrm{~cm}$ of each paste per ceramic plaque was dispensed on a mixing paper, both pastes were mixed with a plastic spatula for 10 s to obtain a uniform paste, immediately it was charged and dispensed into each mold compartment using a universal syringe (Mark IIIpTM, Centrix, CT, USA) without separating its tip from the dispensed mass until filling the compartment.
Variolink II- Adhesive Resin Cement- Two dispensers $(\mathrm{VL})$

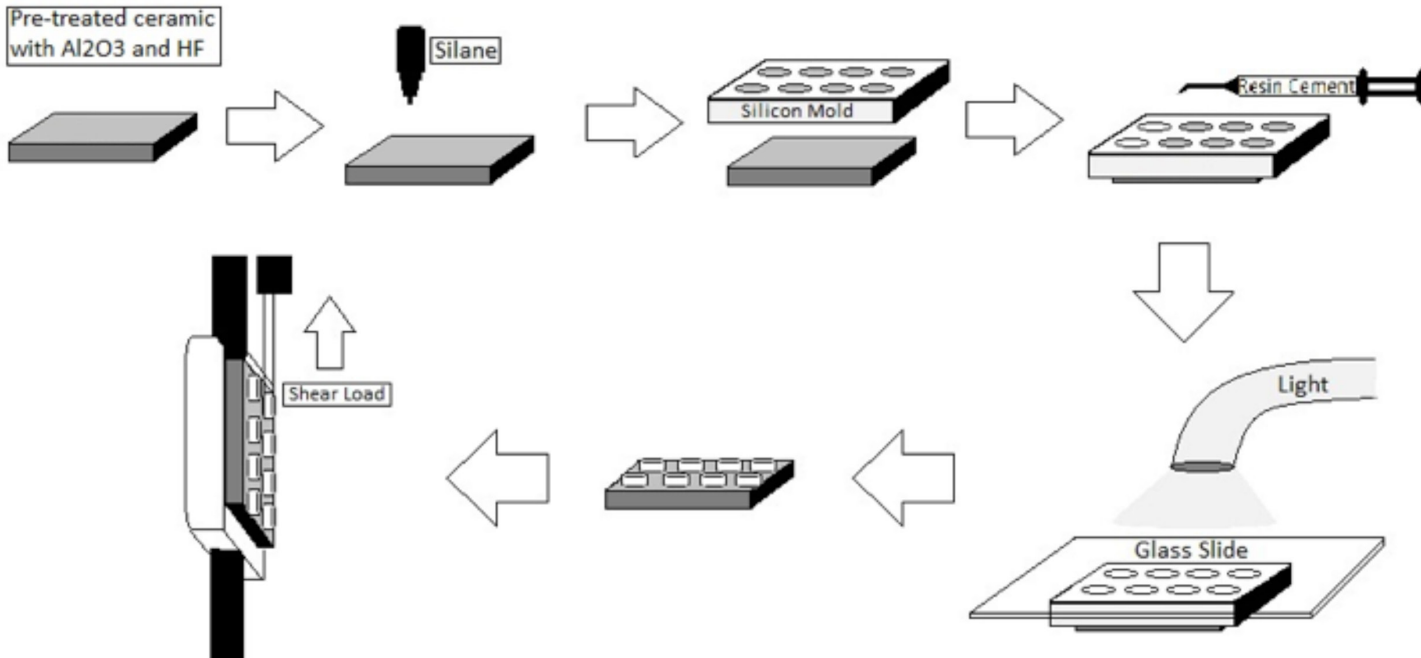

Scheme 1. Schematic illustration of the methodology process. 
For failure pattern evaluation, all specimens were mounted on aluminum stubs with the aid of carbon ribbon, sputter coated with gold/palladium powder (SCD 050; Balzers, Schaan, Liechtenstein) and then examined using a scanning electron microscope (SEM) (JSM 5600 LV; JEOL, Tokyo, Japan) operating at $15 \mathrm{kV}$. Photomicrographs of representative areas of the fractured surfaces were taken at different magnifications for fracture pattern evaluation and then classified according to the following criteria: $A D-C C$, adhesive failure between ceramic and resin cement/adhesive system (when employed); C-AS, cohesive failure in adhesive system (when employed); C-CE, cohesive failure within the ceramic; $\mathrm{C}-\mathrm{RC}$, cohesive failure in resin cement and MIX, mixture of various patterns in the same specimen.

\section{RESULTS}

Two-way ANOVA statistical analysis revealed that the factors "Resin cement" and "silane-solution" significantly influenced the $\mu S B S(p=0.00001)$.
Likewise, significant differences were found in the interaction between the two factors ( $p=0.00001)$. All $\mu$ SBS mean values, data distribution and standard deviation per each group are illustrated in Figure 1.

Spreading data ranged from 2.8 MPa to 48.4 MPa as shown in Fig. 1. Tukey test $(p<0.05)$ showed that treating the glass-ceramic with a conventional silane (AS) produced significantly higher $\mu S B S$ values compared with the ceramic primer (CP) and the universal adhesive (SU). When treated with AS, cements RelyX ARC (AR) and VarioLink II (VL) obtained the statistically highest results, but VL was not significantly different from RelyX Ultimate (RU), RelyX UNICEM 2 (U2) and BiFix (BF) (p>0.05) (Fig. 1). When treatment SU was applied, cements VL and $\mathrm{RU}$ obtained the significantly highest values among all cements $(p<0.05)$. However, RU was statistically not different from $U 2$ and $A R(p>0.05)$. The lowest $\mu S B S$ mean for this treatment was obtained by BF that by the way was not significantly different from AR ( $p>0.05)$ (Fig. 1). When specimens were treated

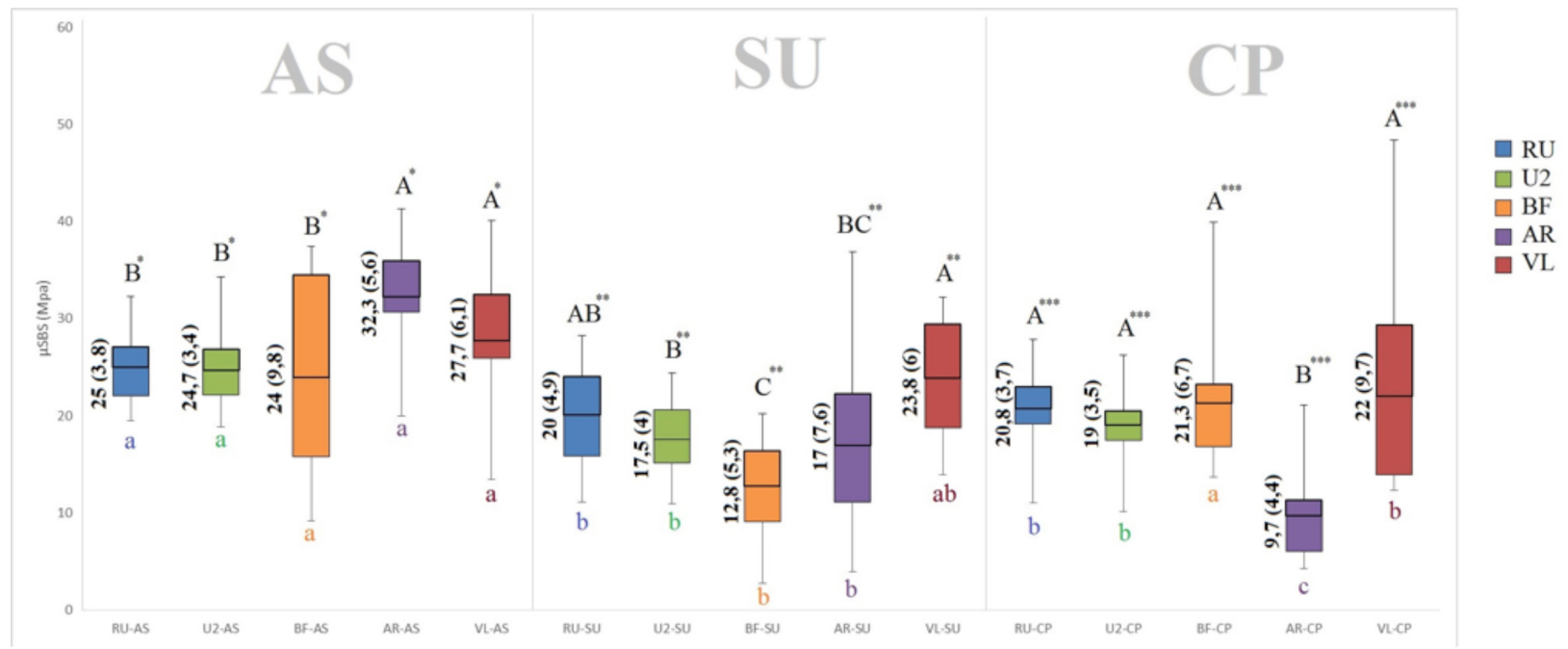

Figure 1. Boxplot of the $\mu \mathrm{SBS}$ results. The box represents the spreading of the data between the first and third quartile. The central horizontal line represents the mean. Mean is also presented in numbers and the standard deviation in parenthesis next to the mean value. The whiskers mark the maximum and minimum value measured. Groups with the same letter are not statistically different $(p<0.05)$. Comparisons must be made between capital letters with the same superscript symbol and between lowercase letters with the same color. Symbology; Resin Cements: Rely X Ultimate (RU), UNICEM 2 (U2), BiFix (BF), Rely X ARC (AR), Vario Link II (VL). Silane Treatment: Rely X Ceramic Primer (AS), Scotchbond Universal (SU), Clearfil Ceramic Primer (CP). 


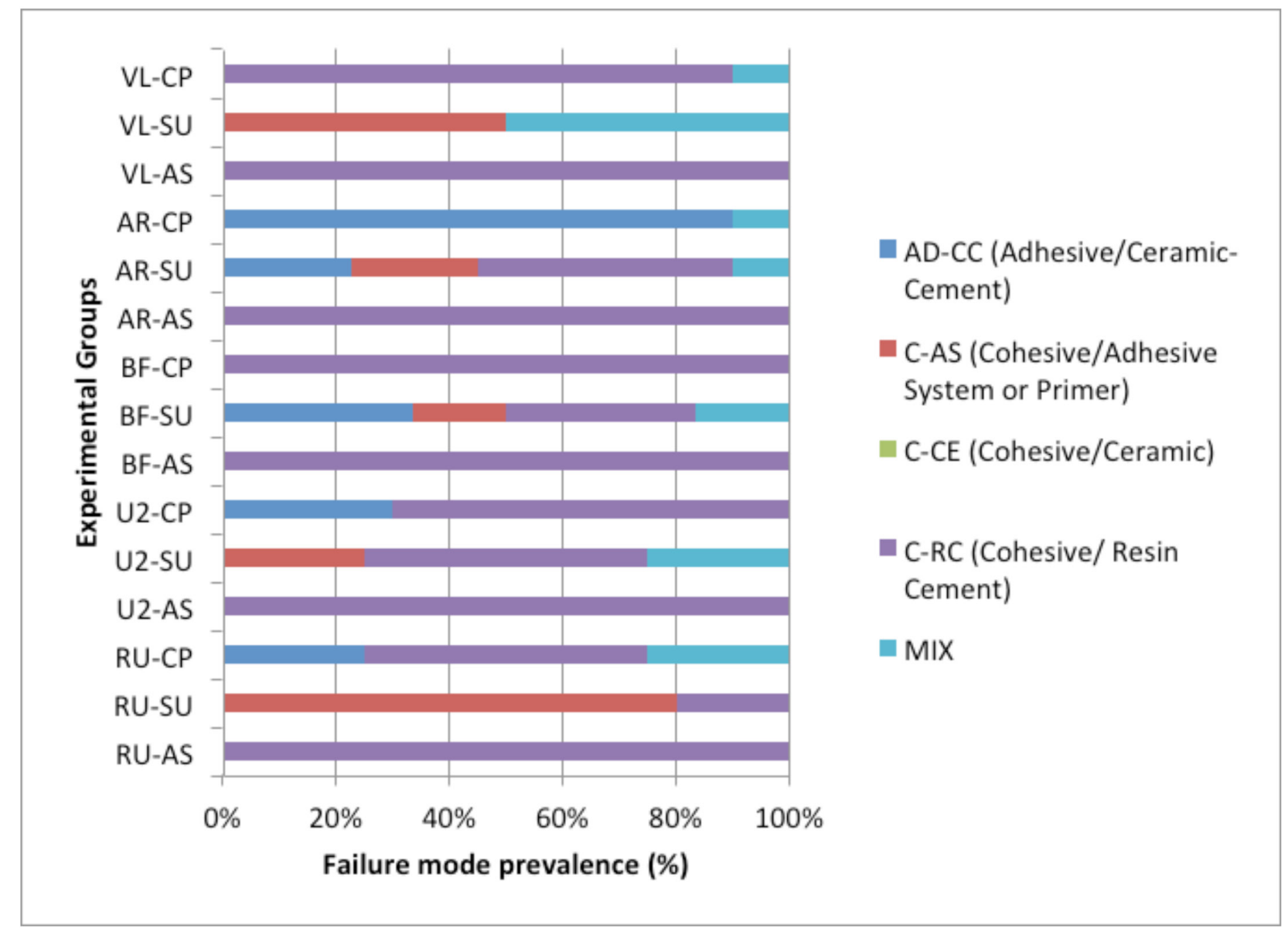

Figure 2. Results of the SEM failure analysis for all experimental groups. Abbreviations: Rely X Ceramic Primer (AS), Scotchbond Universal (SU), Clearfil Ceramic Primer (CP), RelyX Ultimate (RU), RelyX UNICEM 2 (U2), BiFix (BF), RelyX ARC (AR), Vario Link II (VL). 


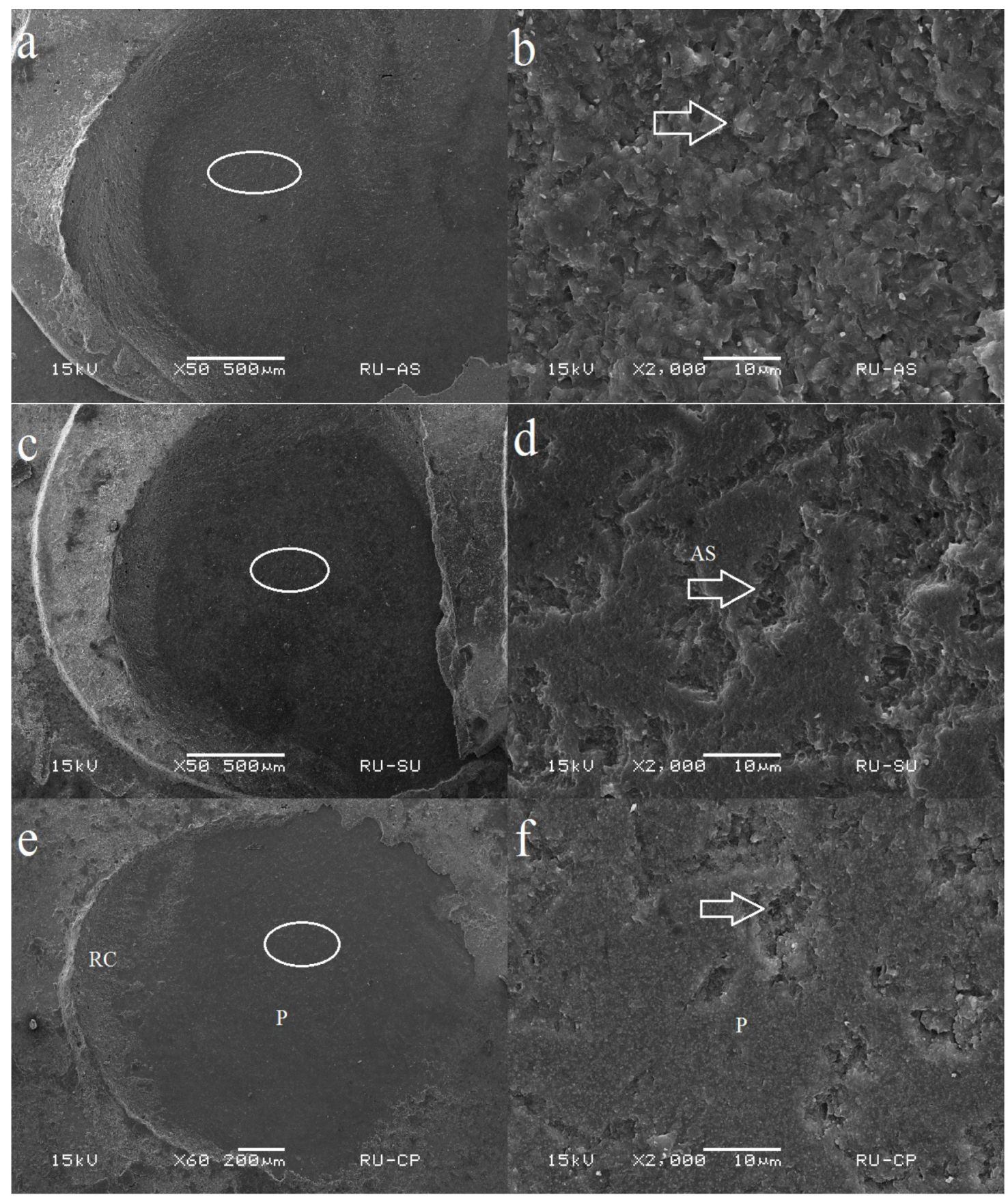

Figure 3. (a) Fracture pattern on the glass-ceramic side of RU-AS showing a predominant cohesive failure in resin cement with irregular resin cement particles agglomeration within the fracture area; (b) Amplification of the circled area in Fig. 3a, note some resin cement particles (arrow) agglomerated; (c) Fracture pattern on the glass-ceramic side of RU-SU showing a predominant cohesive failure in adhesive system with irregular adhesive agglomeration covering the ceramic surface; (d) Amplification of the circled area in Fig. 3c, adhesive system agglomeration segments can be seen (AS) separated for some "spaces" possibly product of an irregular polymerization process (arrow); (e) Fracture pattern on the glass-ceramic side of RU-CP showing a mixed failure in resin cement with one resin cement sections (RC) and other areas of the primer layer $(P)$ covering the ceramic surface; (f) Amplification of the circled area in Fig. 3e, where the primer layer (P) is covering most of ceramic area letting some areas uncovered (arrow) also probably due to an irregular polymerization process. 


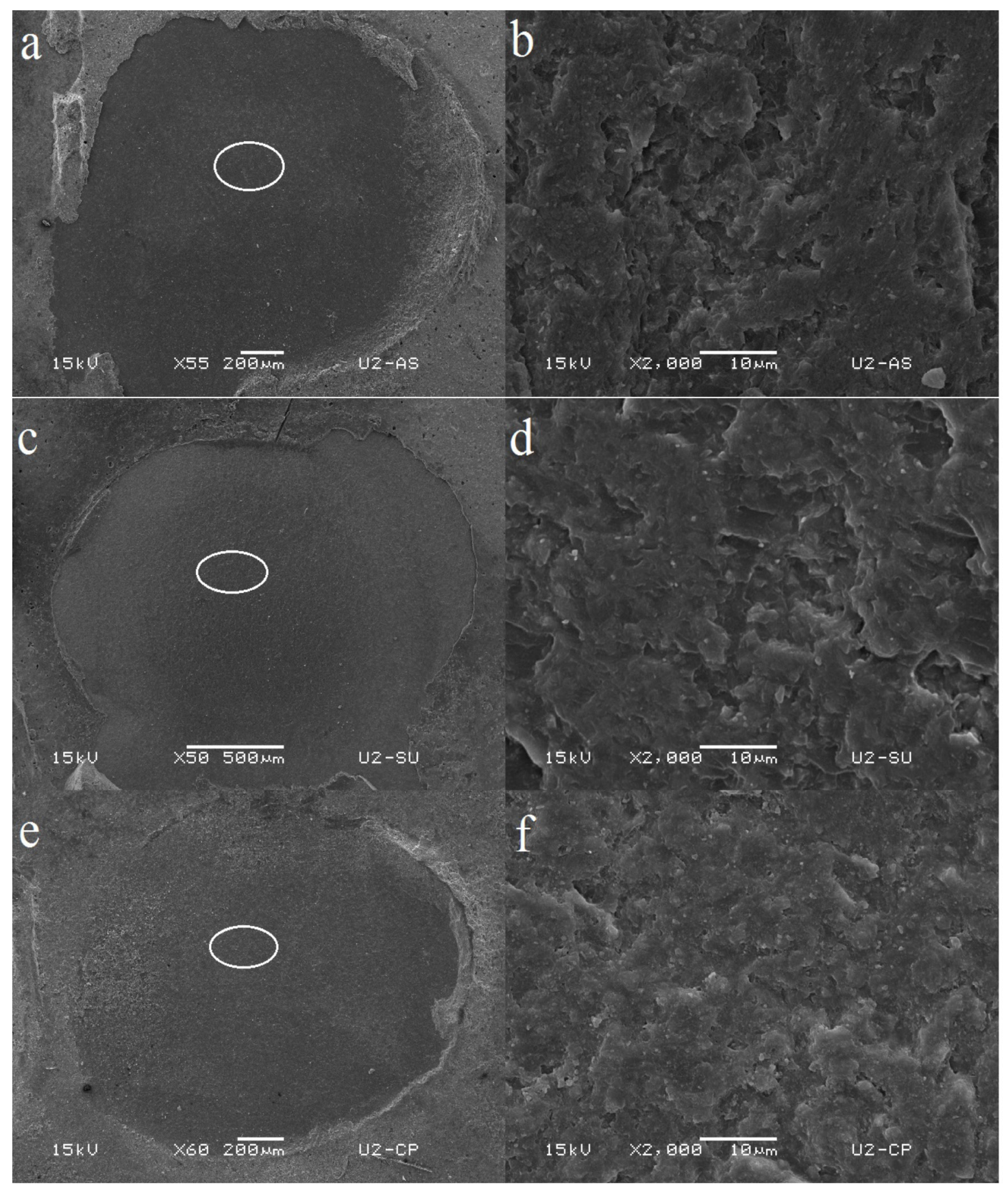

Figure 4. (a) Fracture pattern on the glass-ceramic side of U2-AS showing a predominant cohesive failure in resin cement with irregular resin cement particles agglomeration within the fracture area; (b) Amplification of the circled area in Fig. 4a, when resin cement agglomeration can be observed; (c) Fracture pattern on the glass-ceramic side of U2-SU showing also a predominant cohesive failure in resin cement but closer to the interface; (d) Amplification of the circled area in Fig. 4c, also resin cement agglomerations can be seen; (e) Fracture pattern on the glass-ceramic side of U2-CP showing a predominant cohesive failure in resin cement with irregular resin cement particles agglomeration within the fracture area; (f) Amplification of the circled area in Fig. 4e, where resin cement agglomerations can also be noted. 


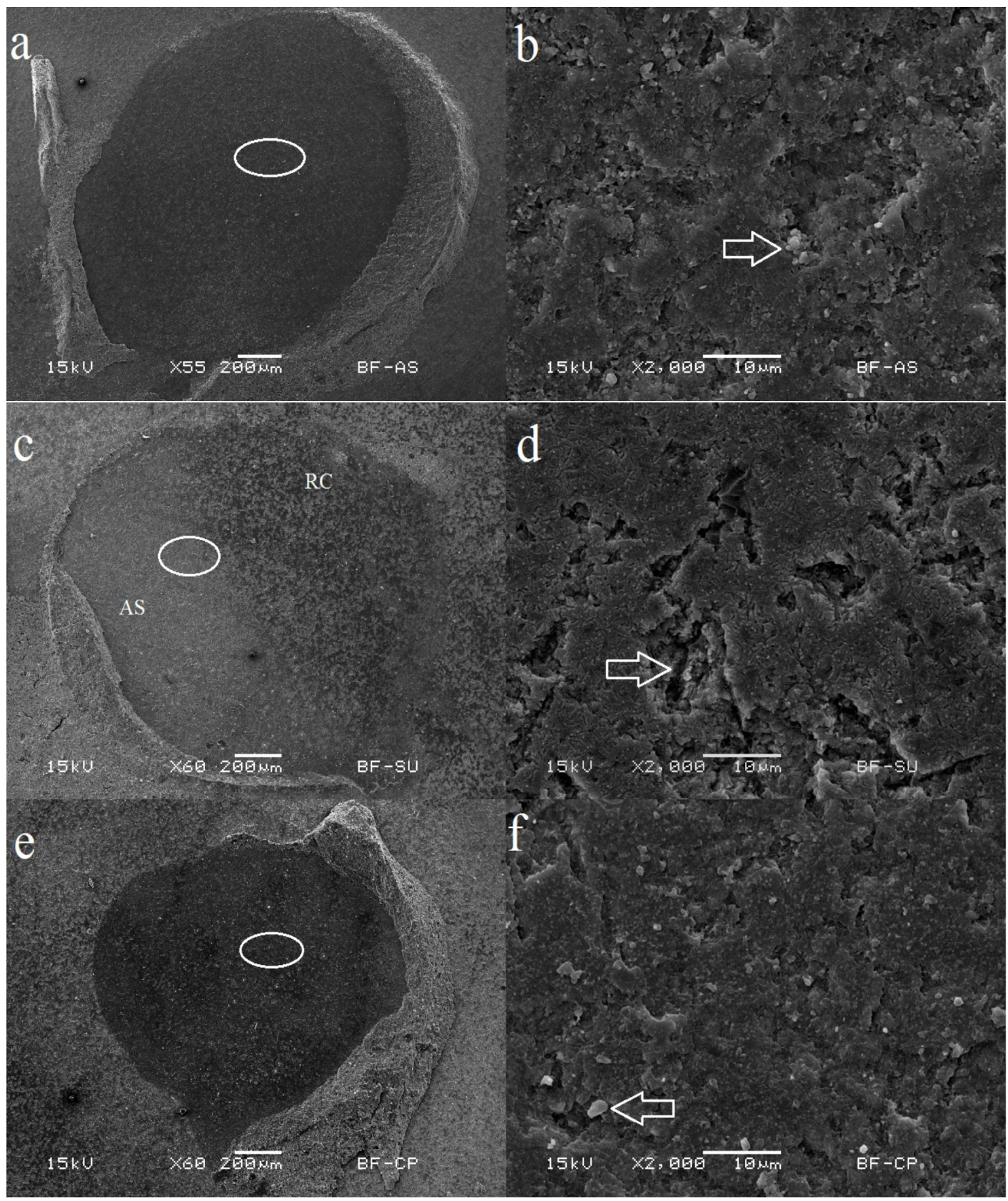

Figure 5. (a) Fracture pattern on the glass-ceramic side of BF-AS showing a predominant cohesive failure in resin cement with irregular resin cement particles agglomeration within the fracture area; (b) Amplification of the circled area in Fig. 5a, note some resin cement particles (arrow) within the agglomeration; (c) Fracture pattern on the glass-ceramic side of BF-SU showing a mixed failure in which one region is covered by the adhesive system (AS) and other area with some resin cement particles (RC); (d) Amplification of the circled area in Fig. 5c, where an adhesive layer is partially covering the ceramic surface very close to the interface and also some "spaces" (arrow) within the covered surface can be seen probably due to an incomplete polymerization in some areas; (e) Fracture pattern on the glass-ceramic side of BF-CP showing a predominant cohesive failure in resin cement with resin cement particles agglomeration within the fracture area; $(f)$ Amplification of the circled area in Fig. 5e, note some resin cement particles (arrow) within the agglomeration. 


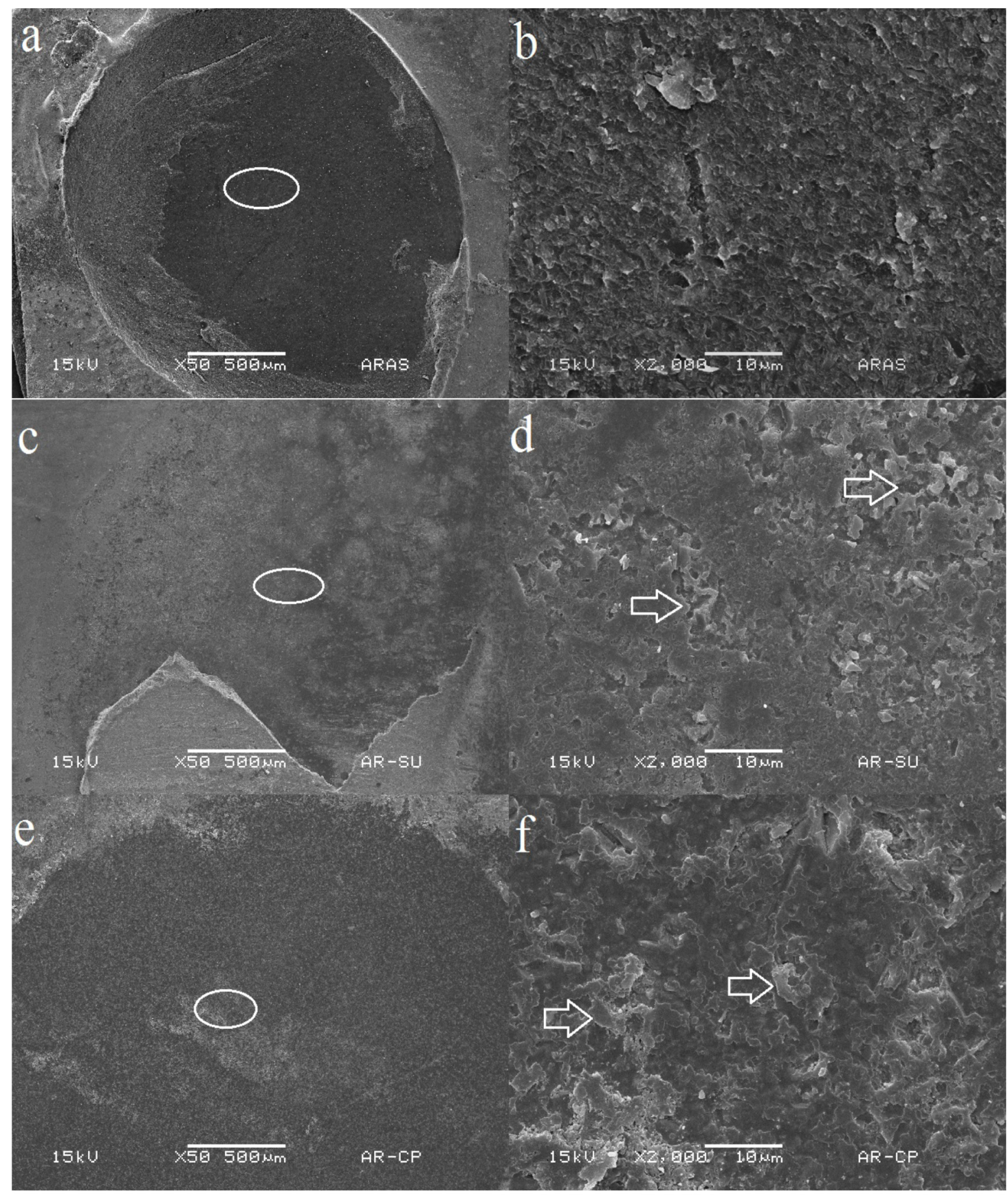

Figure 6. (a) Fracture pattern on the glass-ceramic side of AR-AS showing a predominant cohesive failure in resin cement with irregular resin cement particles agglomeration within the fracture area; (b) Amplification of the circled area in Fig. 6a, where a pretty uniform resin cement layer can be seen; (c) Fracture pattern on the glass-ceramic side of AR-SU showing an mixed failure; (d) Amplification of the circled area in Fig. 6c, where an irregular adhesive system layer covering the ceramic surface can be seen with some amorphous areas (arrow), suggesting incomplete polymerization in those areas within the adhesive-cement interface; (e) Fracture pattern on the glass-ceramic side of AR-CP showing a predominant adhesive failure between ceramic and resin cement; (f) Amplification of the circled area in Fig. 6e, note some amorphous areas (arrow) covering the ceramic surface, suggesting incomplete polymerization regions within the primer-cement interface. 


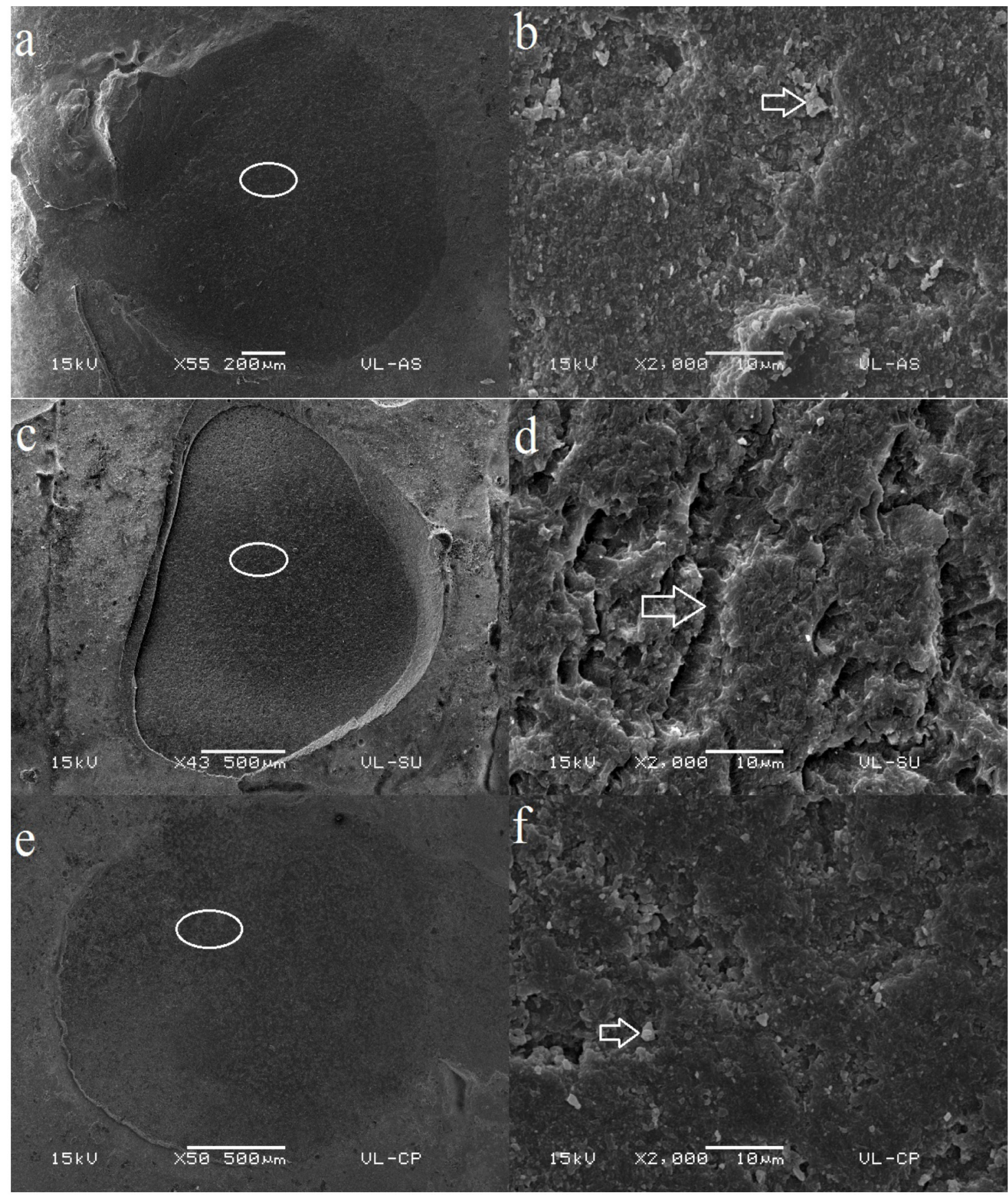

Figure 7. (a) Fracture pattern on the glass-ceramic side of VL-AS showing a predominant cohesive failure in resin cement; (b) Amplification of the circled area in Fig. 7a, when resin cement agglomeration and some particles (arrow) can be observed; (c) Fracture pattern on the glass-ceramic side of VL-SU showing a predominant cohesive failure in adhesive system; (d) Amplification of the circled area in Fig. 7c, adhesive system agglomeration segments covering the ceramic surface can be seen and also some "spaces" (arrow) within the agglomeration suggesting an incomplete polymerization in those areas; (e) Fracture pattern on the glass-ceramic side of VL-CP showing a predominant cohesive failure in resin cement with irregular resin cement particles agglomeration within the fracture area; (f) Amplification of the circled area in Fig. 7e, note some resin cement particles (arrow) within the layer. 
with $\mathrm{CP}, \mathrm{AR}$ presented the significantly lowest mean within the groups $(p<0.05)$ (Fig. 1). Cements RU, $\mathrm{U} 2$ and VL showed significantly higher values when treated with $\mathrm{AS}$ than when treated with $\mathrm{SU}$ and $\mathrm{CP}$ $(p<0.05)$. BF registered lower results when treated with SU than with $A S$ and $C P(p<0.05)$. In the case of AR, AS produced the statistically highest values, followed by SU and CP $(p<0.05)$ (Fig. 1).

Results from SEM fracture pattern analysis are presented in Fig. 2. Representative photomicrographs from all groups are shown from Figure 3 through 7. All groups treated with AS presented C-RC failure pattern and it was also recurrent in most $\mathrm{CP}$ groups. Generally, fracture patterns AD-CC and MIX were mostly prevalent in groups with lower $\mu$ SBS values. In general SU groups showed the most variable failure pattern within all groups (Figs. 3 through 7).

\section{DISCUSSION}

As it is well known two major interfaces are involved in the luting process of an indirect glass-ceramic restoration: tooth/luting agent and luting agent/ceramic material. On this regard, it is clinically relevant to achieve an optimal bonding performance in both interfaces. Thus, the present investigation aimed to study the ceramic/cement interface and two of the main factors involved with it: silanization and its interaction with different resin-cements.

To assess bonding performance of ceramic/ cement interface, a well-established $\mu$ SBS method was used (Shimada et al., 2002). This method uses a thin wire close and parallel to the bonding area instead of a blade, in order to better distribute the stress in the surrounding specimen area (Dehoff et al., 1995). Also, the usage of a micro-specimen leads to a greater uniformity on that stress distribution and avoids better the undesirable cohesive failure in substrate, producing more "realistic" failure patterns than when using bigger specimens (Della Bona et al., 2000; Della Bona et al., 2003; Pisani-Proenca et al., 2006).

Overall, statistical evaluation revealed significant differences between the groups (Tukey test, $p<0.05)$, as well as that factors "resin cement" and "silane solution" did influenced ceramic/cement bonding performance, so the hypothesis set in this study must be accepted (Two-way ANOVA, $p=0.00001$ ).

Three conventional adhesive and two selfadhesive resin cements were used as luting agents. A conventional silane (AS), a built-in silane universal adhesive (SU) and a ceramic primer containing silane and MDP were employed as silanization agents.

Regarding "silane solution", when specimens were treated with AS all cements tested presented their statistically highest results compared with the other treatments, so in this conditions, all cements performed pretty well (Fig. 1). This can be illustrated with the fact that with AS, cements obtained a relatively uniform data distribution and so a stable behavior with this treatment could be presumed with the only exception of BF that showed a non-uniform data distribution (Fig. 1). RelyX ceramic primer (AS), contains a pre-hydrolyzed silane (3-Methacryloxypropyltrimethoxysilane, MPS) mixed in one bottle with water and ethanol (according to material MSDS). So, MPS present in AS is a ready-for-use silane and capable to bond methacrylate groups via $\mathrm{OH}$ - groups and also it may improve the wettability of the ceramic surface and promote better interaction between ceramic and cement as it has been previously suggested (Lung\&Matinlinna, 2012; Meng et al., 2011). In fact, a good interaction between resin-cement and ceramic surface could be presumed for AS groups in this study as all specimens presented C-RC failure mode (Figs. 2, 3a and b, 4a and b, 5a and $b, 6 a$ and $b, 7 a$ and $b$ ), sign of a more intimate contact and higher ceramic-cement bond strength 
according to previous findings (Pollington et al., 2010). Another important factor in this regard, is that silanes form three different oligomer layers when applied as a sole-coat (Ishida\&Koenig, 1980) but just the first one is capable to bond with ceramics (Berg\&Jones, 1998). So, it is important to get the thinnest layer possible and eliminate the solvent and other by-products of bonding reaction to improve adhesion (Roulet et al., 1995). In our study, a single silane layer was applied and dried (following manufacturers' instructions) with the intention of eliminating most of solvents and by-products and improve chemical adhesion. Moreover, sandblasting and HF etching performed an all ceramic plaques may have promoted mechanical interlocking and enhancing adhesion (Tian et al., 2014). This combined mechanical/ chemical bonding is considered to be the most accepted glass-ceramic pre-treatment and it has been reported that it provides the highest ceramic/ cement bonding (Brentel et al., 2007; Kitayama et al., 2010; Shimada et al., 2002). With those issues in mind and in light of our results, it can be affirmed that this protocol (AS) continues to be the preferred glass ceramic pre-treatment.

A universal ceramic primer $(\mathrm{CP}$, containing silane and MDP) and a silane-containing multimode adhesive system (SU, containing also MDP and silane) were also employed. Kern and Wegner (Kern\&Wegner, 1998) first reported that resin cements containing phosphate monomers could form a water-resistant chemical bond with zirconia (Wegner\&Kern, 2000). Furthermore, literature reports that acidic monomers rapidly hydrolyze silane coupling agents, enhancing the polysiloxane bonding network needed to form a chemical union of resin cement with zirconia and also with glass ceramics (Kitayama et al., 2010; Tanaka et al., 2008). Probably, with this intention is that phosphate monomers and silane are mixed as in SU and CP. Conversely in the present study, most groups treated with SU and CP obtained lower values than AS, so the supposed combined benefit of silane and MDP didn't perform better than the sole-silane (Fig. 1). This may be due in part, to the addition of MDP to the silane-solution, in the sense of having less silane quantity per area in contact with ceramic surface and available to perform the link with resin cement (Ikemura et al., 2011) (in contrast with the sole silane solution) and also hindering the elimination of solvents and other byproducts obstructing the formation of complete condensation reactions needed to form siloxane network (Shen et al., 2004). According to this, is that some "spaces" could be observed in SEM images of some groups employing SU and $\mathrm{CP}$, suggesting incomplete polymerization areas possibly produced in part by water release (silane condensation reaction byproduct) within the interface (Figs. 3d and f, 5d, 6d, 6f and 7d). Furthermore, the addition of other components may affect negatively the adhesion process and may promote the formation of a thicker silane layer with more oligomer presence that may be also detrimental hindering an intimate interaction and consequently bonding performance (Tian et al., 2014; Roulet et al., 1995; Monticelli et al., 2006).

$\mathrm{CP}$ and SU behaved relatively similar within the cements, just BF and AR obtained different values between those treatments (Fig. 1). In the case of BF, it obtained lower results with SU than with $A S$ and $C P$ and it also was the lowest on SU group together with AR (Fig. 1). Thus, it could be presumed that some incompatibility between SU and BF may have caused bond strength decrease and produced a very variable failure pattern prevalence (Fig. 2) as well as some possible incomplete polymerization areas visible on SEM images (Fig. 5c and d). Also, BFSU shows a pretty uniform data distribution on a low range (Fig. 1). Several studies have confirmed some incompatibilities between dual-cure (or chemically-cure) composites and some acidic monomers present in some simplified adhesives and ceramic primers (Chen\&Suh, 2013; Schittly et al., 2010; Suh et al., 2003). This occurs primarily 
because the acidic monomers in the oxygen inhibition layer can deactivate the tertiary amines (needed to produce chemical polymerization), affecting the chemical polymerization system on self-curing and dual-curing resin cements (Suh et al., 2003). Hence, highly acidic one-step adhesives or primers greatly decrease ceramic/cement bond strength when using self-cure or dual-cure resin cements with it, as probably happened in this case (Shittly et al., 2010).

The other cement that behaved different with SU and CP was AR. This cement particularly obtained the highest values for AS, lower for SU and the lowest for CP (Fig. 1). It was also the lowest mean value among all cements when treated with CP. Hence, it could be presumed that also some incompatibility as the one mentioned before may exist between AR and CP, as it behaved very well with $A S$ and quite normal with SU but not very well with CP. Also its data distribution is relatively constant on a low range (Fig. 1). That incompatibility may be due to the fact that $\mathrm{CP}$ is a ceramic primer containing an acidic monomer (MDP) with a $\mathrm{pH}$ value of approximate 2.5 (according to manufacturer) and AR a dualcure resin cement containing an amine and benzoyl peroxide as chemical polymerization system. That situation matches the one described previously about incompatibility between acidic primers/adhesives and dual-cure resin cements. Additionally, the more prevalent failure mode was $A D-C C$ and it is associated with low $\mu S B S$ values. Also it could be observed on SEM images, some areas of apparent rejection and maybe incomplete polymerization between the primer layer and the resin cement (Fig. 6d and f).

In the case of $\mathrm{RU}$, manufacturer claims that this cement is designed to work well with SU as it has integrated a "dark cure activator" so its self-curing portion would not be affected with acidic one-bottle adhesives. In the case of $\mathrm{U} 2$, as it is a self-adhesive resin cement it already has acidic monomers on its composition, so its chemical polymerization component may be acidic-resistant already. In the present study $\mathrm{RU}$ showed a pretty uniform behavior with the three silane-solutions and also the most homogenous data distribution together with U2 (Fig. 1). So it could be presumed that $\mathrm{RU}$ and $\mathrm{U} 2$ really did not suffer greater affectation when used along with acidic one-bottle solutions. In fact, instructions for use of SU recommend the employment of that activator (available as a separate product) when uses SU along with another dual-cure/self-cure resin cement than RU. As one of our objectives was to investigate the interaction between the pure cements and the silane-solutions, we did not use that activator with any of the cements used on the study.

Interesting was that despite this theoretical problem, just BF-SU and AR-CP showed some kind of decrease on $\mu S B S$ values. In the case of $\mathrm{VL}$, it obtained also a high mean value with the three solutions. It presented more variable data distribution when used with SU and CP signalizing a less constant behavior in those conditions but nothing as critical as AR (Fig. 1). This may be remarkable because VL uses also benzoil peroxide/ amine as chemical polymerization mechanism (as $A R$ ) and so a major affectation would be expected when used with SU and CP. So it can be inferred that VL's polymerization depends more on the physical polymerization system than on the chemical polymerization component, different than $A R$ and possibly explaining why it was not equally affected by acidic solutions. So, that negative interaction may be material dependent, as each specific composition may influence the cements' behavior against simplified acidic solutions containing silane. This is clinically relevant as the main purpose of those one-bottle/universal solutions is to simplify clinical steps and diminish the quantity of clinical steps to be used in the cementation process. So the clinician may pay attention to this interaction issues in order to avoid any problem 
that could affect bonding performance when combining different silane-containing-solutions with different dual-cure resin cements.

\section{CONCLUSIONS}

Within the limitations of this in vitro study we can conclude the following:

1.The sole-silane solution performed better than the silane-containing primer and the silanecontaining universal adhesive when used as silanization agents.

2.In general, both alternative silane-solutions (SU and $\mathrm{CP}$ ) performed relatively well and very similar between each other.

3.Compatibility between those alternative silanesolutions (as they are acidic solutions) and dualcure resin cements may be material dependent as some dual-cure resin cements may use an acid-sensitive chemical polymerization system and some other may not.

\section{ACKNOWLEDGEMENTS}

The authors want to thank University of Costa Rica, FOP-UNICAMP, CAPES and Brazilian authorities for all the support given in many ways to Dr. Murillo-Gómez to perform his researching activities in Brazil. These results were used by Dr. Murillo-Gomez as part of his master's degree thesis.

\section{REFERENCES}

Anagnostopoulos T, Eliades G, Palaghias G. Composition, reactivity and surface interaction of three dental silane primers. Dent Mater 1993;9(3):182-190.

Berg J, Jones FR. The role of sizing resins, coupling agents and their blends on the formation of the interphase in glass fibre composites. Composite 1998;Part A(29A):1261-1272.

Blatz MB, Dent M, Sadan A, Kern M. Resin-ceramic bonding: a review of the literature. J Prosthet Dent 2003;89(3):268-274.
Blatz MB, Sadan A, Martin J, Lang B. In vitro evaluation of shear bond strengths of resin to densely sintered high-purity zirconium-oxide ceramic after long-term storage and thermal cycling. J Prosthet Dent 2004;91(4):356-362.

Borges GA, Spohr AM, De Goes MF, Sobrinho LC, Chan DC. Effect of etching and airborne particle abrasion on the microstructure of different dental ceramics. J Prosthet Dent 2003;89(5):479-488.

Brentel SA, Özcan M, Valandro LF, Guimarães Alarça L, Amaral R, Bottino MA. Microtensile bond strength of a resin cement to feldpathic ceramic after different etching and silanization regimens in dry and aged conditions. Dent Mater 2007;23(11): 1323-1331.

Chen L, Suh Bl. Effect of hydrophilicity on the compatibility between a dual-curing resin cement and one-bottle simplified adhesives. J Adhes Dent 2013;15(4):325-331.

De Munck J, Van Landuyt K, Peumans M, Poitevin A, Lambrechts P, Braem M, et al. A critical review of the durability of adhesion to tooth tissue: methods and results. J Dent Res 2005;84(2):118-132.

Dehoff PH, Anusavice KJ, Wang Z. ThreeDimensional finite-element analysis of the shear bond test. Dent Mater 1995;11(2):126-131.

Della Bona A, Anusavice KJ, Mecholsky Jr JJ. Failure analysis of resin composite bonded to ceramic. Dent Mater 2003;19(8):693-699.

Della Bona A, Anusavice KJ, Shen C. Microtensile strength of composite bonded to hot-pressed ceramics. J AdhesDent 2000;2(4):305-313.

Denry I, Kelly JR. State of the art of zirconia for dental applications. Dent Mater 2008;24(3):299-307. Eames WB, Rogers LB, Feller PR, Price WR. Bonding agents for repairing porcelain and gold: an evaluation. Oper Dent 1977;2(3):118-124.

Edelhoff D, Özcan M. To what extent does the longevity of fixed dental prostheses depend on the function of the cement? Working group 4 materials: cementation. Clin Oral Implants Res 2007;18(3):193-204. 
Ferracane JL, Stansbury JW, Burke FJT. Selfadhesive resin cements-chemistry, properties and clinical considerations. J Oral Rehabil 2011;38(4):295-314.

Filho AM, Vieira LC, Araujo E, Monteiro Junior S. Effect of different ceramic surface treatments on resin microtensilebond strength. J Prosthodont 2004;13(1):28-35.

Ikemura K, Tanaka H, Fujii T, Deguchi M, Negoro $\mathrm{N}$, Endo T, Kadoma Y. Design of a new, multipurpose, light-curing adhesive comprising a silane coupling agent, acidic adhesive monomers and dithiooctanoate monomers for bonding to varied metal and dental ceramic materials. Dent Mater 2011;30(4):493-500.

Ishida $\mathrm{H}$, Koenig JL. A Fourier-transform infrared spectroscopic study of the hydrolytic stability of silane coupling agents on E-glass fibers. J Polymer Sci, Polymer Physics 1980;18(9):1931-1943.

Kelly JR, Denry I. Stabilized zirconia as a structural ceramic: an overview. Dent Mater 2008;24(3):289-298.

Kern M, Wegner SM. Bonding to zirconia ceramic: adhesion methods and their durability. Dent Mater 1998;14(1):64-71.

Kitayama S, Nikaido T, Takahashi R, Zhu L, Masaomi I, Foxton R, Sadr A, Tagami J. Effect of primer treatment on bonding of resin cements to zirconia ceramic. Dent Mater 2010;26(5):426-432.

Kramer N, Lohbauer U, Frankenberger R. Adhesive luting of indirect restorations. Am J Dent 2000;13:60D-76D.

Lung CY, Matinlinna JP. Aspects of silane coupling agents and surface conditioning in dentistry: An overview. Dent Mater 2012;28(5):467-477. Matinlinna JP, Lassila LV, Ozcan M, Yli-Urpo A, Vallittu PK. An introduction to silanes and their clinical applications in dentistry. Int $\mathrm{J}$ Prosthodont 2004;17(2):155-164.

Meng X, Yoshida K, Taira Y, Kamada K, Luo X. Effect of siloxane quantity and ph of silane coupling agents and contact angle of resin bonding agent on bond durability of resin cements to machinable ceramic. J Adhes Dent 2011;13(1):71-78.

Moharamzadeh K, Hooshmand T, Keshvad A, Van Noort R. Fracture toughness of a ceramic-resin interface. Dent Mater 2008;24(2):172-177.

Monticelli F, Toledano M, Osorio R, Ferrari M. Effect of temperature on the silane coupling agents when bonding core resin to quartz fiber posts. Dent Mater 2006;22(11):1024-1028.

Peumans M, De Munck J, Van Landuyt KL, Poitevin A, Lambrechts P, Van Meerbeek B. Eightyear clinical evaluation of a 2-step self-etch adhesive with and without selective enamel etching. Dent Mater 2010;26(2):1176-1184.

Peumans M, Van MeerbeekB, Yoshida Y, Lambrechts P, Vanherle G. Porcelain veneers bonded to tooth structure: an ultra-morphological FESEM examination of the adhesive interface. Dent Mater 1999;15(2):105-119.

Pisani-Proenca J, Erhardt MC, Valandro LF, Gutierrez-AcevesG, Bolanos-Carmona MV, Del Castillo-Salmeron R, Bottino MA. Influence of ceramic surface conditioning and resin cements on microtensile bond strength to a glass ceramic. J Prosthet Dent 2006;96(6):412-417.

Pollington S, Fabianelli A, Van Noort R. Microtensile bond strength of a resin cement to a novel fluorcanasite glass-ceramic following different surface treatments. Dent Mater 2010;26(9):864-872.

Roulet JF, Soderholm KJ, Longmate J. Effects of treatment and storage conditions on ceramic/ composite bond strength. Journal of Dental Research 1995;74(1):381-387.

Sadowsky SJ. An overview of treatment considerations for esthetic restorations: a review of the literature. J Prosthet Dent 2006;96(6):433-442.

Schittly E, Bouter D, Le Goff S, Degrange M, Attal JP. Compatibility of five self-etching adhesive systems with two resin luting cements. J Adhes Dent 2010:12(2):137-142. 
Shen C, Oh WS, Williams JR. Effect of postsilanization drying on the bond strength of composite to ceramic. J Prosthet Dent 2004;91(5):453-458.

Shimada Y, Yamaguchi S, Tagami J. Micro-shear bond strength of dual-cured resin cement to glass ceramics. Dent Mater 2002;18(5):380-388.

Suh Bl, Feng L, Pashley DH, Tay FR. Factors contributing to the incompatibility between simplified-step adhesives and self-cured or dualcured composites. Part III. Effect of acidic resin monomers. J Adhes Dent 2003:5(4):267-282.

Tanaka R, Fujishima A, Shibata Y, Manabe A, Miyazaki T. Cooperation of phosphate monomer and silica modification on zirconia. J Dent Res 2008;87(7):666-670.
Tian T, Tsoi JK, Matinlinna JP, Burrow MF. Aspects of bonding between resin luting cements and glass ceramic materials. Dent Mater 2014;30(7):e147-e162.

Van Meerbeek B, De Munck J, Yoshida Y, Inoue S, Vargas $M$, Vijay $P$ et al. Buonocore memorial lectura. Adhesion to enamel and dentin: current status and future challenges. Oper Dent 2003;28(3):215-235.

Van Meerbeek B., Yoshihara K., Yoshida Y., Mine A., De Munck J., Van Landuyt K.L. State of the art of self-etch adhesives. Dent Mater 2011;27(1):17-28.

Wegner SM, Kern M. Long-term resin bond strength to zirconia ceramic. J Adhes Dent 2000;2(2):139-147. 